\title{
Mechanisms of angina relief in patients after coronary artery bypass surgery ${ }^{1}$
}

\author{
MOUNIR MNAYER, ROBERT A. CHAHINE, AND ALBERT E. RAIZNER \\ From the Department of Medicine, Baylor College of Medicine and the Section of Cardiology at the \\ Veterans Administration Hospital, Houston, Texas, U.S.A.
}

The mechanisms underlying the relief of angina after coronary bypass surgery have been studied by analysing the results of the baseline and follow-up treadmill tests on patients included in a prospective randomised study of surgical versus medical treatment of stable angina pectoris. There were 22 surgically treated patients and 35 medically treated patients, whose endpoint on the initial treadmill tests was angina with concomitant ischaemic ST depression. At one year, 91 per cent of the surgically treated patients had no chest pain during the exercise test while only 11 per cent of the medically treated patients were free from angina $(P<0 \cdot 001)$. Exercise tolerance was significantly better in both groups but improvement was greater in the surgically treated patients (exercise tolerance increased by $98 \%$ compared with $28 \%$ ). The product of heart rate and systolic blood pressure measured at the maximal exercise level was also increased significantly in the surgically treated patients, whereas this product decreased slightly in the medically treated patients. Of the surgically treated patients, 59 per cent had ischaemic ST depression on the exercise electrocardiogram but did not develop anginal pain, compared with only 9 per cent of the medically treated patients $(P<0 \cdot 001)$. These data suggest that in addition to increased coronary blood flow, for which the increased product of heart rate and blood pressure is indirect evidence, trauma to nerves and possibly other nonspecific factors related to surgery may be important mechanisms contributing to the relief of angina after coronary bypass surgery.

The surgical treatment of ischaemic heart disease using the saphenous vein bypass technique has become widely accepted. This procedure has resulted in excellent symptomatic results with complete relief of, or considerable improvement in angina in a high percentage of patients (Favaloro, 1972; Reul et al., 1972; Hall et al., 1973; Segal et al., 1973; Najmi et al., 1974; Mathur and Guinn, 1975; Ross, 1975). The preliminary results of a randomised study performed in our hospital (Mathur and Guinn, 1975) clearly showed that angina was improved and the quality of life better in the operated patients compared with the medically treated patients.

Despite extensive use of this surgical procedure, a major question that remains unanswered concerns the mechanisms responsible for the symptomatic improvement. It is believed that restoration of adequate coronary blood flow with consequent improvement in oxygen delivery to the ischaemic myocardium is the main factor underlying pain

${ }^{1}$ Presented in part at the 48th Scientific Sessions of the American Heart Association, Anaheim, California, November 1975.

Received for publication 4 October 1976 relief after coronary artery bypass. However, significant improvement or complete relief of angina has been noted in some patients with occluded grafts (Griffith et al., 1973a; Di Luzio et al., 1974; Campeau et al., 1976). Also, many surgically treated patients have been found to develop ischaemic ST depression on follow-up treadmill testing, but without chest pain (Bartel et al., 1973; Berndt et al., 1975). These observations raised the question whether the increased oxygen delivery was the sole mechanism underlying the improvement of angina, and attempts have been made to identify other contributory factors. These include: (1) infarction of ischaemic myocardium during operation (Hultgren et al., 1971; Brewer et al., 1973; Griffith et al., 1973b; Di Luzio et al., 1974; Ross, 1975), (2) possible improvement of left ventricular function (Chatterjee et al., 1972; Hammermeister et al., 1974), (3) denervation of ischaemic areas (Soloff, 1973; Ross, 1975), and (4) the placebo effect of surgery (Cobb et al., 1959; Dimond et al., 1960; Spodick, 1971; Campeau et al., 1976).

The purpose of this report is to elucidate this problem further by analysing the results of treadmill exercise testing in two similar groups of 
patients with angina, selected randomly for surgical or medical treatment.

\section{Patients and methods}

The treadmill exercise data of the patients included in a prospective randomised study of surgical versus medical treatment of stable angina pectoris (Mathur and Guinn, 1975) were reviewed. Since the object of this study was to evaluate the mechanisms underlying the relief of chest pain after operation, the subjects were selected for inclusion in this analysis if they satisfied the following criteria: (1) availability of an adequate prerandomisation treadmill test where the endpoint was definite angina with accompanying ischaemic ST depression, (2) availability of a follow-up treadmill test at 1 year or more after randomisation.

The treadmill tests were performed according to the Bruce protocol (Bruce and Hornsten, 1969). Two modified bipolar transthoracic electrocardiographic leads were monitored, using the V5 and V6 positions. Resting records of these two leads were obtained both in the sitting and standing positions before starting the exercise test. Records were then obtained at 1-minute intervals during exercise, at the end of the exercise period, and subsequently at 3-minute intervals until return to baseline. The blood pressure was determined using a standard clinical sphygmomanometer every 3 minutes, before increasing the exercise load from one stage to the next. The patients were exercised to symptomatic

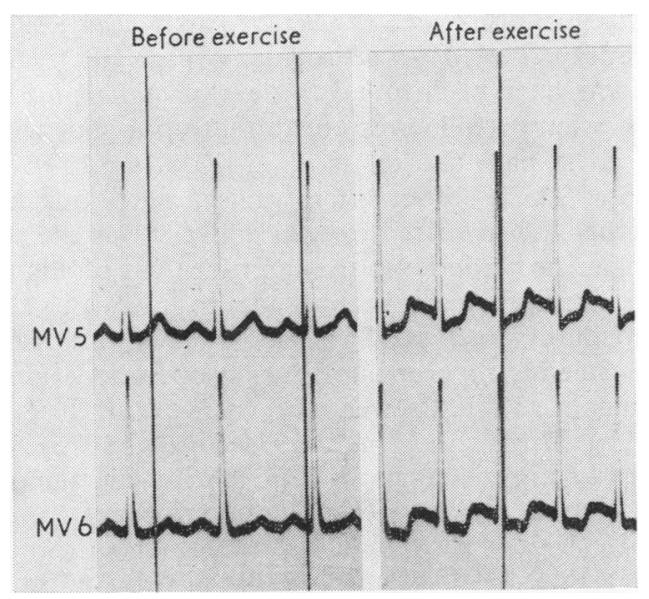

Fig. 1 An example of the treadmill test : electrocardiograms (bipolar transthoracic leads in $V 5$ and V6 positions) recorded from one of the surgical patients who stopped because of fatigue. Note the exercise-induced ischaemic ST segment depression. endpoints: moderately severe angina, dyspnoea, or exhaustion.

A treadmill test was interpreted as positive for ischaemia if the exercise resulted in $1 \mathrm{~mm}$ or more of horizontal or downsloping ST segment lasting $0.08 \mathrm{~s}$ or more, in the absence of digitalis, diuretics, or other drugs known to produce false positive tests (Fig. 1). A test was considered negative if no significant ST segment changes occurred though the patient attained 85 per cent or more of his predicted maximal heart rate. It was considered inconclusive if the patient had no significant ST changes but failed to attain 85 per cent of predicted maximal heart rate or if ST changes occurred but the patient was receiving digitalis or other drugs known to produce such ST changes.

All patients who were included in the prospective randomised study underwent cardiac catheterisation and coronary angiography before randomisation. The presence of critical coronary arterial stenosis $(70 \%$ or more decrease in lumen diameter) in one or more major vessels was a prerequisite for inclusion in the study. Catheterisation and angiography were repeated about 1 year after randomisation on all patients in both treatment groups. Informed consent was obtained for all the studies performed. The statistical analysis was performed using the Student's $t$ test and $\chi^{2}$ test.

\section{Results}

There were 57 patients, allocated randomly to surgical or medical treatment, who satisfied our selection criteria (availability of a prerandomisation positive treadmill with angina as the endpoint and availability of follow-up treadmill at one year or more). Twenty-two patients had had a coronary bypass operation and of these $20(91 \%)$ had no chest pain during the 1-year follow-up treadmill test, while of the 35 who were randomised to the medical treatment group only $4(11 \%)$ had no chest pain during the treadmill test performed at one year $(P<0.001)$.

The treadmill data of the surgical patients are summarised in Table 1 and those of the medical patients in Table 2. Comparison of the baseline data of the surgical and medical patients showed no significant difference in duration of exercise, maximal heart rate attained, maximal systolic pressure, or maximal product of heart rate $x$ systolic pressure (the double product). Fig. 2 shows a schematic display of the exercise tolerance time and the double product observed in the surgical and medical groups. Both surgically and medically treated patients significantly improved their exercise tolerance at 1 year, though the 
Table 1 Surgical group

\begin{tabular}{lccll}
\hline & Baseline & One year & $\%$ Change & $P$ \\
\hline $\begin{array}{l}\text { Duration of } \\
\text { exercise }\end{array}$ & $3 \mathrm{~min} 48 \mathrm{~s}$ & $7 \mathrm{~min} 32 \mathrm{~s}+98$ & $<0.001$ \\
$\begin{array}{l}\text { Maximal heart rate } \\
\text { Maximal systolic } \\
\text { blood pressure }\end{array}$ & $134 \pm 6$ & $150 \pm 5$ & +12 & $<0.01$ \\
$\begin{array}{c}\text { Maximal double } \\
\text { product }\end{array}$ & $150 \pm 5$ & $177 \pm 8$ & +18 & $<0.01$ \\
\hline
\end{tabular}

Table 2 Medical group

\begin{tabular}{lcrll}
\hline & Baseline & One year & $\%$ Change $P$ \\
\hline $\begin{array}{l}\text { Duration of } \\
\text { exercise }\end{array}$ & $3 \min 57 \mathrm{~s}$ & $5 \min 5 \mathrm{~s}$ & +28 & $<0.001$ \\
$\begin{array}{l}\text { Maximal heart rate } \\
\begin{array}{l}\text { Maximal systolic } \\
\text { blood pressure }\end{array}\end{array} 138 \pm 3$ & $148 \pm 4$ & $145 \pm 3$ & -2 & $\mathrm{NS}$ \\
$\begin{array}{l}\text { Maximal double } \\
\text { product }\end{array}$ & $20960 \pm 787$ & $18469 \pm 608$ & -12 & $<0.01$ \\
\hline
\end{tabular}

Table 3 Results of treadmill test at 1 year

\begin{tabular}{lccl}
\hline & $\begin{array}{c}\text { Medical } \\
\text { treatment }\end{array}$ & Surgery & $P$ \\
\hline $\begin{array}{l}\text { Ischaemic ST depression and } \\
\text { angina }\end{array}$ & $28(80 \%)$ & $2(9 \%)$ & $<0.001$ \\
$\begin{array}{l}\text { Ischaemic ST depression, no } \\
\text { angina }\end{array}$ & $3(9 \%)$ & $13(59 \%)$ & $<0.001$ \\
$\begin{array}{l}\text { Negative treadmill test } \\
\text { Inconclusive }\end{array}$ & $0(0 \%)$ & $6(27 \%)$ & $<0.05$ \\
& $4(11 \%)$ & $1(5 \%)$ & NS \\
\hline & 35 & 22 & \\
\hline
\end{tabular}

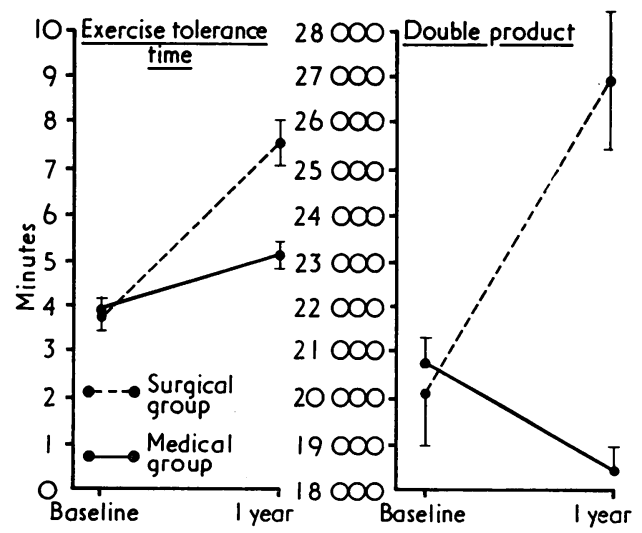

Fig. 2 Effect of surgical versus medical management on the exercise tolerance and the maximal double product (systolic blood pressure $\times$ heart rate). Note that there was no significant difference between the base-line values. Exercise tolerance improved significantly in both groups but more so in the surgical group. The double product increased significantly in the surgical group but decreased in the medical group. surgical patients clearly performed better than the medical patients. The double product also increased significantly in the surgical patients, while in the medical patients it decreased slightly.

Further analysis of the treadmill data obtained at 1 year, relating the presence or absence of chest pain to the presence or absence of ischaemic ST segment changes on the monitored electrocardiographic leads, is summarised in Table 3 and displayed schematically in Fig. 3. At 1 year, 13 surgical patients (59\%) had ischaemic ST depression without angina, while this occurred in only $3(9 \%)$ of the medically treated patients $(P<0 \cdot 001)$. The overwhelming majority of the medical patients $(80 \%)$ had ST depression and angina.

In an attempt to find a possible explanation for this higher incidence in the surgical group of ischaemic ST depression without angina on the treadmill test, the following factors were carefully reviewed in the 13 patients with this finding: (1) presence of perioperative myocardial infarction: only $1(8 \%)$ had a definite perioperative infarct diagnosed on the basis of the appearance of new pathological $Q$ waves on the electrocardiogram; (2) myocardial function, as determined by left ventriculography: there was no significant difference from baseline at 1 year (ejection fraction $64 \% \pm$ at one year compared to $66 \% \pm 4$ at baseline); (3) patency of grafts: of the 25 grafts, $22(88 \%)$ were patent upon restudy at 1 year; (4) duration of exercise was increased by 125 per cent from baseline ( $7^{\prime} 58^{\prime \prime}$ vs. $3^{\prime} 33^{\prime \prime} ; \mathrm{P}<0.01$ ); (5 maximum double product was increased by 33 per cent from baseline (27 830 vs. 20920 ; $\mathrm{P}<0.01)$.

In the search for further factors responsible for the improvement of angina, other than the increase of blood flow to ischaemic areas, we also reviewed

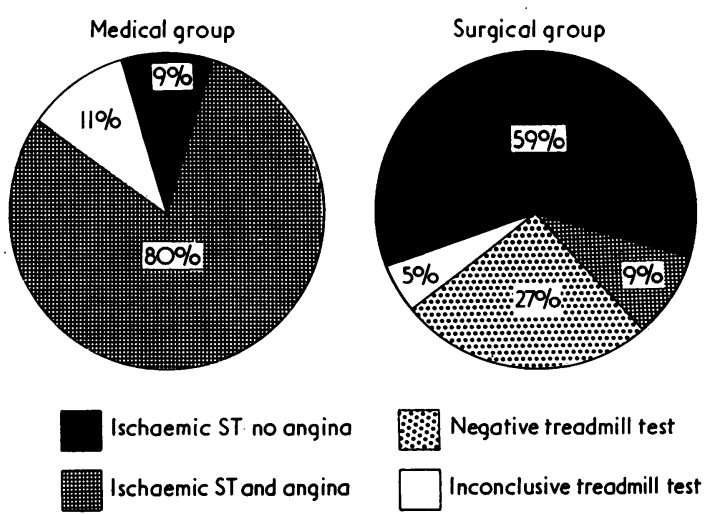

Fig. 3 Schematic presentation of the treadmill results at one year in the surgical and medical groups. 
Table 4 Analysis of 7 surgical patients with all grafts occluded

\begin{tabular}{lccc}
\hline & Baseline & One year & $\%$ Change \\
\hline Duration of exercise & $4 \min 15 \mathrm{~s}$ & $7 \min 37 \mathrm{~s}+80$ \\
Maximal heart rate & 155 & 161 & +4 \\
Maximal systolic blood pressure & 159 & 160 & \\
Maximal double product & 23940 & 25890 & +9 \\
\hline
\end{tabular}

all the surgical patients included in the randomised study, searching for cases with occlusion of all grafts. We found 7 such patients, none of whom was included in the present series because they did not satisfy the selection criteria. The treadmill data are summarised in Table 4. Despite the fact that these patients had all their grafts occluded, their exercise tolerance also improved, averaging 80 per cent increase from baseline, and 4 of the 7 had no angina upon treadmill testing at 1 year. There was no statistically significant increase in their maximal double product.

\section{Discussion}

Comparing the results of surgical and medical management, as assessed by treadmill testing at 1 year after starting treatment, it is apparent that the surgically treated patients were able to exercise longer with significantly lower incidence of chest pain than the medically treated patients. These results compare well with others' observations of significant improvement of exercise performance after bypass surgery (Mason et al., 1971; Bergman et al., 1971; Bartel et al., 1973; Lapin et al., 1973; Aronow and Stemmer, 1974; Knoebel et al., 1974; Merrill et al., 1975). It is reasonable to attribute the high incidence of pain relief after surgery to increased oxygen delivery to the ischaemic myocardium through restoration of coronary blood flow. This contention is supported indirectly by the significant increase in the maximum double product (34\% increase) and the high percentage of patent bypass grafts, with reasonably good filling of the distal vessels, 1 year after randomisation.

However, a large proportion of the surgically treated patients $(13 / 22)$ showed ischaemic changes on the electrocardiogram during the treadmill test without developing angina. This observation has also been made by others (Bartel et al., 1973; Berndt et al., 1975) and suggests that there may be additional mechanisms of pain relief after coronary arterial bypass grafting. Several authors (Hultgren et al., 1971; Brewer et al., 1973; Griffith et al., 1973b; Di Luzio et al., 1974; Ross, 1975) have considered the role of non-fatal myocardial in- farction in the symptomatic relief of patients by eliminating or reducing the ischaemic focus. However, this factor could not account for the relief of angina in our patients since only one out of 13 had evidence of perioperative myocardial infarction. Another possible explanation is that the perivascular nerves accompanying the coronary arteries are divided or traumatised during the procedure (Soloff, 1973; Ross, 1975). This interruption of the pain pathway from the heart might increase exercise tolerance, and account for the ischaemic ST segment response to the exercise test without angina. Our data favour this possibility since, in the comparable group of medically treated patients where no trauma to nerves can be postulated, only $3(9 \%)$ showed ischaemic ST depression without angina and the difference between the medical and surgical groups was statistically significant in this respect $(\mathbf{P}<0.001)$. This mechanism appears more likely than a pure placebo effect, since a placebo effect may also be produced by medical treatment. The additional observation that 7 patients all of whose grafts were occluded significantly increased their exercise tolerance, and that 4 of these patients had no angina on the treadmill test performed at one year, also supports the view that trauma to nerves and perhaps a nonspecific placebo effect of surgery may be important factors in the relief of angina.

It is, therefore, concluded that there is more than one mechanism involved in the relief of angina after coronary arterial bypass. Our data suggest that in addition to increased coronary blood flow, trauma to nerves and possibly other non-specific factors related to surgery may be important contributing mechanisms.

We gratefully acknowledge Drs. Henry McIntosh, Gene Guinn, Virendra Mathur, Robert Luchi, Mahir Awdeh, Alfredo Montero, and Tetsuo Ishimori for advice, suggestions, and help in carrying out this study, and Dr. John Thornby for the statistical analysis.

\section{References}

Aronow, W. S., and Stemmer, E. A. (1974). Bypass graft surgery versus medical therapy of angina pectoris. American Fournal of Cardiology, 33, 415-420.

Bartel, A. G., Behar, V. S., Peter, R. H., Orgain, E. S., and Kong, Y. (1973). Exercise stress testing in evaluation of aortocoronary bypass surgery, report of 123 patients. Circulation, 48, 141-148.

Bergman, S. A., Urschel, H. C., and Blomqvist, G. (1971). Pre- and postoperative exercise testing in patients undergoing direct myocardial revascularization (abstract). Circulation, 43-44, Suppl. II, II-141. 
Berndt, T. B., Miller, D. C., Silverman, J. F., Stinson, E. B., Harrison, D. C., and Schroeder, J. S. (1975). Coronary bypass surgery for unstable angina pectoris. American fournal of Medicine, 58, 171-176.

Brewer, D. L., Bilbro, R. H., and Bartel, A. G. (1973). Myocardial infarction as a complication of coronary bypass surgery. Circulation, 47, 58-64.

Bruce, R. A., and Hornsten, T. R. (1969). Exercise stress testing in evaluation of patients with ischemic heart disease. Progress in Cardiovascular Diseases, 11, 371-390.

Campeau, L., Heitz, A., Crochet, D., and Lespérance, J. (1976). Long term improvement of effort angina following aortocoronary saphenous vein bypass graft surgery: increased myocardial blood flow or pain denial placebo effect? (abstract). American fournal of Cardiology, 37, 126.

Chatterjee, K., Swan, H. J. C., Parmley, W. W., Sustaita, H., Marcus, H., and Matloff, J. (1972). Depression of left ventricular function due to acute myocardial ischemia and its reversal after aortocoronary saphenous-vein bypass. New England fournal of Medicine, 286, 1117-1122.

Cobb, L. A., Thomas, G. I., Dillard, D. H., Merendino, K. A., and Bruce, R. A. (1959). An evaluation of internalmammary-artery ligation by a double-blind technic. New England fournal of Medicine, 260, 1115-1118.

Di Luzio, V., Roy, P. R., and Sowton, E. (1974). Angina in patients with occluded aorto-coronary vein grafts. British Heart fournal, 36, 139-147.

Dimond, E. G., Kittle, C. F., and Crockett, J. E. (1960). Comparison of internal mammary artery ligation and sham operation for angina pectoris. American fournal of Cardio$\log y, 5,483-486$.

Favaloro, R. (1972). Direct and indirect coronary surgery. Circulation, 46, 1197-1207.

Griffith, L., Achuff, S., Conti, C. R., Humphries, J. O. Brawley, R., Gott, V., and Ross, R. (1973a). Changes in intrinsic coronary circulation and segmental ventricular motion after saphenous-vein coronary bypass graft surgery. New England fournal of Medicine, 288, 589-595.

Griffith, L., Achuff, S., Humphries, J. O., Conti, R. C., Brawley, R., Gott, V., and Ross, R. (1973b). Mechanisms of symptomatic improvement after coronary bypass graft surgery (abstract). American fournal of Cardiology, 31, 137.

Hall, R. J., Dawson, J. T., Cooley, D. A., Hallman, G. L., Wukasch, D. C., and Garcia, E. (1973). Coronary artery bypass. Circulation, 47-48, Suppl. III, III-146-150.

Hammermeister, K. E., Kennedy, J. W., Hamilton, G. W., Stewart, D. K., Gould, K. L., Lipscomb, K., and Murray, J. A. (1974). The effect of vein bypass grafting on resting left ventricular function. New England fournal of Medicine, $290,186$.
Hultgren, H., Miyagawa, M., Buck, W., and Angell, W. (1971). Ischemic myocardial injury during coronary artery surgery. American Heart fournal, 82, 624-631.

Knoebel, S. B., McHenry, P. L., Phillips, J. F., and Lowe, D. K. (1974). Effect of aortocoronary bypass grafts on myocardial blood flow reserve and treadmill exercise tolerance. Circulation, 50, 685-693.

Lapin, E. S., Murray, J. A., Bruce, R. A., and Winterscheid, L. (1973). Changes in maximal exercise performance in the evaluation of saphenous vein bypass surgery. Circulation, 47, 1164-1173.

Mason, D. T., Amsterdam, E. A., Miller, R. R., Hughes, J. L., Bonanno, J. A., Iben, A. B., Hurley, E. J., Massumi, R. A., and Zelis, R. (1971). Consideration of the therapeutic roles of pharmacologic agents, collateral circulation and saphenous vein bypass in coronary artery disease. American Fournal of Cardiology, 28, 608-613.

Mathur, V. S., and Guinn, G. A. (1975). Prospective randomized study of coronary bypass surgery in stable angina. The first 100 patients. Circulation, 51-52, Suppl. I, I-133-139.

Merrill, A. J., Jr., Thomas, C., Schechter, E., Cline, R., Armstrong, R., and Stanford, W. (1975). Coronary bypass surgery. Value of maximal exercise testing in assessment of results. Circulation, 51-52, Suppl. I, I-173-176.

Najmi, M., Ushiyama, M., Blanco, G., Adam, A., and Segal, B. (1974). Results of aortocoronary artery saphenous vein bypass surgery for ischemic heart disease. American fournal of Cardiology, 33, 42-48.

Reul, G. J., Morris, G. C., Howell, J. F., Crawford, E. S., and Stelter, W. J. (1972). Current concepts in coronary artery surgery. A critical analysis of 1287 patients. Annals of Thoracic Surgery, 14, 243-259.

Ross, R. S. (1975). Ischemic heart disease: an overview. American fournal of Cardiology, 36, 496-505.

Segal, B. L., Likoff, W., Najmi, M., and Linhart, J. W. (1973). Saphenous vein bypass surgery for coronary artery disease. American Fournal of Cardiology, 32, 1010-1013.

Soloff, L. A. (1973). Effects of coronary bypass procedures. New England fournal of Medicine, 288, 1302-1303.

Spodick, D. H. (1971). Revascularization of the heart numerators in search of denominators. American Heart fournal, 81, 149-157.

Requests for reprints to Dr. Robert A. Chahine, Chief, Section of Cardiology, Veterans Administration Hospital, 2002 Holcombe Boulevard, Houston, Texas 77211, U.S.A. 